\title{
Cidadania e Deficiência
}

\section{Citizenship and Disability}

\section{Marcelo Santos Baia}

Como citar esse artigo. BAIA, M. S. Cidadania e Deficiência. Mosaico -Revista Multidisciplinar de Humanidades, Vassouras, v. 12, n. 2, p. 91-100, mai./ago. 2021.

Nota da Editora. Os artigos publicados na Revista Mosaico são de responsabilidade de seus autores. As informações neles contidas, bem como as opiniões emitidas, não representam pontos de vista da Universidade de Vassouras ou de suas Revistas.

\section{Resumo}

A história da deficiência no mundo passa por episódios de discriminação e pela busca deste grupo pelos mesmos direitos que as outras pessoas que não possuem qualquer deficiência ou dificuldade. Por meio de vários diplomas legais específicos de seus países, como a constituição e de tratados entre países, como a Convenção sobre os Direitos das Pessoas com Deficiência, os deficientes foram sendo amparados legalmente, chegando ao ponto de a discriminação contra um deficiente ser considerada crime. Contudo, além da questão da discriminação, os deficientes acabam não tendo seus direitos constitucionais respeitados devido à falta de acessibilidade, de acesso à Educação e, consequentemente, à uma vida mais digna. Este artigo tem por objetivo geral apresentar a relação existente entre a cidadania e deficiência. Para isso, ambos os termos serão não apenas conceituados, mas apresentadas estatísticas referentes à deficiência em Portugal. Por fim, será discutido como a cidadania é o meio de inclusão dos deficientes em Portugal. Para alcançar tais objetivos, utilizou-se como metodologia científica a revisão de literatura de artigos científicos, dissertações, livros, além de documentos oficiais relacionados ao tema.

Palavras-chave: Deficiência. Cidadania. Inclusão.

\begin{abstract}
The history of disability in the world goes through episodes of discrimination and the pursuit of this group for the same rights as other people who do not have any deficiency or difficulty. Through various legal instruments specific to their countries, such as the constitution and treaties between countries, such as the Convention on the Rights of Persons with Disabilities, disabled persons have been legally protected, reaching the point of discrimination against a disabled person. However, in addition to the issue of discrimination, the disabled end up not having their constitutional rights respected due to lack of accessibility, access to education and, consequently, to a more dignified life. This time article by general objective present the relationship between citizenship and disability. For this purpose, both terms will be not only conceptualized but presented statistics regarding disability in Portugal. Finally, it will be discussed how citizenship is the means of inclusion of the disabled in Portugal. In order to reach these objectives, a scientific methodology was used to review the literature of scientific articles, dissertations, books, and official documents related to the subject, namely, disability and citizenship.
\end{abstract}

Keywords: sDisability. Citizenship. Inclusion.

\section{Introdução}

A cidadania é considerada como um dos preceitos mais básicos para que o indivíduo seja reconhecido pelo Estado e pelos seus compatriotas, sendo deste modo equivalente a um status não apenas moral, mas também legal.

Trata-se de algo que deveria ser inerente às sociedades contemporâneas, onde todos os membros de uma comunidade são reconhecidos e têm direitos e deveres iguais. Contudo, no que diz respeito aos indivíduos portadores de deficiência, o conceito de cidadania acaba não tendo seu pleno teor respeitado.

Por terem características especiais em decorrência da sua dificuldade, ao contrário do que acontece com a maior parte da população, os portadores de deficiência têm dificuldades de exercer plenamente a sua cidadania, estando sujeitos a vários tipos de discriminação.

Problemas relacionados à acessibilidade, à falta de adequação das metodologias de ensino, assim como de recursos e de pessoal qualificado, acabam impedindo os deficientes de terem acesso à Educação de qualidade desde as séries iniciais. Esse cenário acaba se perpetuando na sua vida, o que tem consequências em várias esferas, como a econômica e social. Os deficientes acabam vivendo à margem quando poderiam ter suas capacidades e qualidades exercidas plenamente.

Por meio de diversos diplomas legais, os países buscaram meios de reduzir a desigualdade entre os que possuem deficiências e os que não possuem, proporcionando a todos o acesso aos direitos básicos, além de buscar combater a discriminação. Contudo,

Afiliação dos autores

Mestrando em Ciências Jurídicas na Universidade Ual (Universidade Autônoma Luís de Camões - Lisboa) Portugal.

* Email de correspondência: marcelo.advogado.rj@gmail.com 
esses diplomas, isoladamente, não são capazes de proporcionar a essa parcela da população seus plenos direitos, cabendo aos operadores do Direito atuar nos casos em que os seus direitos como cidadão estão sendo cerceados.

Cabe ao Estado, respeitando e cumprindo o que prevê suas leis e tratados, colaborar para que atos de discriminação, assim como os casos de impedimento ao acesso aos direitos constitucionais, sejam combatidos. E cabe à sociedade fiscalizar se as leis estão sendo cumpridas, para que nenhum cidadão seja prejudicado.

\section{Deficiência}

\section{Conceito e Definição}

A definição exata do que vem a ser a deficiência dependeria de vários pormenores e da sociedade analisada. Contudo, independente da definição, a deficiênciaestarásemprerelacionadaàssuasnecessidades educacionais básicas e também à interação do sujeito com a sociedade. Por muito tempo a deficiência esteve permeada de ignorância, assim como de superstições e crenças, além de uma série de atos de discriminação que, apesar de ocorrerem em menor intensidade, ainda perduram (PORTUGAL, 2006c).

Deficiência: perda ou anormalidade de estrutura ou função psicológica, fisiológica ou anatômica, temporária ou permanente. Incluem-se nessas a ocorrência de uma anomalia, defeito ou perda de um membro, órgão, tecido ou qualquer outra estrutura do corpo, inclusive das funções mentais. Representa a exteriorização de um estado patológico, refletindo um distúrbio orgânico, uma perturbação no órgão (AMIRALIAN et al., 2000, p. 98).

Segundo o texto da Convenção sobre os Direitos das Pessoas com Deficiência, integrante do documento resultante da Convenção das Nações Unidas sobre esses direitos, a deficiência é um conceito que está em constante evolução.

A deficiência resulta da interação entre pessoas com deficiência e as barreiras devidas às atitudes e ao ambiente que impedem a plena e efetiva participação dessas pessoas na sociedade em igualdade de oportunidades com as demais pessoas (ONU, 2011, p.22).

Como foi possível observar, são várias as definições e conceitos associados à deficiência que foram criados ao longo do tempo. Dependendo da definição dada, os organismos governamentais, assim como as instituições sem fins lucrativos voltadas ao amparo, acolhimento e assistência ao deficiente, promoveram suas políticas sociais e assistenciais.
A deficiência pressupõe a existência de variações de algumas habilidades que sejam classificadas como restrições ou lesões. Não existindo um consenso de quais as variações ou habilidades e funcionalidades que caracterizam a deficiência. A variedade de interpretações e experiências em torno do corpo e da relação deste com o ambiente social perpassa grande parte das discussões contemporâneas sobre a deficiência (DINIZ; SQUINCA; MEDEIROS, 2007, p. 3).

Buscando um consenso entre várias definições e conceituações, a OMS (Organização Mundial da Saúde) estabeleceu uma definição acerca da deficiência que tem como foco presença ou não das habilidades do indivíduo, assim como as suas variações, como foi descrito na Classificação Internacional de Funcionalidade, Incapacidade e Saúde (CIF), que colaboram para o entendimento das limitações dos portadores de deficiências.

A maioria dos termos que geram confusão é utilizada com
um significado baseado no sentido comum da linguagem
falada e escrita do dia a dia. Por exemplo, deficiência,
incapacidade e limitação são frequentemente utilizadas
com o mesmo significado nos contextos quotidianos,
embora na versão de 1980 do ICIDH, esses termos
tivessem um significado preciso. Durante o processo de
revisão, o termo "desvantagem" foi abandonado e o termo
"incapacidade" foi utilizado para abranger todas as três
perspectivas - corporal, individual e social. No entanto,
é necessário usar de clareza e precisão para definir os
vários conceitos, de maneira que possam ser escolhidos os
termos apropriados para expressar de forma não ambígua
cada um dos conceitos subjacentes (OMS, 2004, p.185).

Como foi possível observar, este documento buscou também padronizar as metodologias, conceitos e critérios acerca do tema, acabando com as diversas classificações e nomenclaturas, o que dificultava a promoção de ações internacionais em defesa dos deficientes.

Em Portugal, a deficiência pode receber algumas tipificações, podendo ser auditiva, visual, motora, mental, assim como paralisia cerebral. Contudo, independente da classificação da deficiência, o sujeito deve ter seus direitos universais garantidos. Na CIF, a deficiência é expressa como um desvio do que é tido como normal, envolvendo não apenas a aparência física, mas, também, as funções do corpo (ROSÁRIO, 2015).

Tais direitos são descritos em diplomas legais por legisladores que, após discussões políticas, chegam a um consenso das necessidades de um grupo. Esse consenso acaba dando legitimidade às demandas sociais, à sua realidade, sendo ponto importante na garantia da cidadania dos indivíduos.

Outro documento que merece destaque é o Relatório Mundial sobre a Deficiência, que foi publicado pela OMS em 2011, em que consta uma série de recomendações voltadas aos deficientes. Neste relatório, é possível observar a preocupação da OMS com o acesso dos deficientes aos sistemas 
públicos de serviços, estratégias e às políticas públicas, recomendando, assim, que os países invistam em serviços e programas voltados aos deficientes, como a reabilitação treinamento de pessoal (Ibidem).

Vale lembrar que "as decisões tomadas no sistema político, sendo executadas como decisões de um Estado, têm uma maneira peculiar de incidir sobre a realidade social ao alcance do poder de Estado" (FERREIRA et al., 2017).

Portugal, assim como outros países, ratificou um documento denominado Convenção sobre os Direitos das Pessoas com Deficiência (CDPD), que tem como objetivo garantir a todas as pessoas portadores de deficiência "o pleno e igual gozo de todos os direitos humanos e liberdades fundamentais" (PORTUGAL, 2011, online), assim como o respeito e a dignidade. A CDPD prevê que todos são iguais, promovendo, desse modo, a igualdade entre as pessoas.

Artigo 5. ${ }^{\circ}$ Igualdade e não discriminação. 1 - Os Estados Partes reconhecem que todas as pessoas são iguais perante e nos termos da lei e que têm direito, sem qualquer discriminação, a igual proteç̧ão e benefício da lei. 2 - Os Estados Partes proíbem toda a discriminação com base na deficiência e garantem às pessoas com deficiência protecção jurídica igual e efectiva contra a discriminação de qualquer natureza. 3 - De modo a promover a igualdade e eliminar a discriminação, os Estados Partes tomam todas as medidas apropriadas para garantir a disponibilização de adaptações razoáveis. 4 - As medidas específicas que são necessárias para acelerar ou alcançar a igualdade de facto das pessoas com deficiência não serão consideradas discriminação nos termos da presente Convenção (Ibidem).

Tal documento também foi específico no que concerne às mulheres e crianças deficientes, dispensando a estes grupos artigos específicos.

Ainda sobre o direito universal à dignidade, Rosário lembra que o Pacto de São José da Costa Rica (Convenção Americana sobre os Direitos Humanos) possui um artigo "dedicado à proteção da honra e da dignidade, estabelece que toda a pessoa deve ser respeitada em sua honra e dignidade" (ROSÁRIO, 2017, p. 123).

Acercadas mulheres com deficiência, odocumento reconhece que tanto as mulheres quanto as meninas deficientes estão mais suscetíveis à discriminação. Sendo assim, os Estados que aderiram ao pacto em questão se comprometeram a tomar medidas para evitar tal quadro, dando a estas os "pleno e igual exercício de todos os direitos humanos e liberdades fundamentais" (ONU, 2011, p.32).

No que diz respeito às crianças deficientes, o documento dispõe que todos os Estados devem tomar as devidas medidas para garantir às crianças portadoras de deficiência "o pleno exercício de todos os direitos humanos e liberdades fundamentais, em igualdade de oportunidades com as demais crianças" (ONU, 2011, p.32)..

Além da CDPD, Portugal conta também a com a sua Constituição, mais especificamente no artigo $71^{\circ}$, que prevê a igualdade de direitos e deveres dos portadores de deficiência, assim como obriga o Estado, entre outras coisas, a "realizar uma política nacional de prevenção e de tratamento, reabilitação e integração dos cidadãos portadores de deficiência e de apoio às suas famílias" (PORTUGAL, 2005, online); e com o Decreto-lei 319 de 23 de agosto de 1991 que "estabelece o regime educativo especial aplicável aos alunos com necessidades educativas especiais" (PORTUGAL, 1991, online).

Além destes, vale destacar a Lei 38 de 18 de agosto de 2004, que "define as bases gerais do regime jurídico da prevenção, habilitação, reabilitação e participação da pessoa com deficiência" (PORTUGAL, 2004, online); e também a Lei 46 de 28 de agosto de 2006, que "proíbe e pune a discriminação em razão da deficiência e da existência de risco agravado de saúde" (PORTUGAL, 2006b, online).

Apesar de sucessivas propostas legislativas e do continuado desenho de políticas sociais, elaboradas no propalado desígnio de conduzir a uma inclusão social das pessoas com deficiência, a realidade social em Portugal segue dando prova de uma tenaz perpetuação deste quadro excludente (MARTIS, 2017, p. 23).

A entrada de Portugal na União Europeia (UE) proporcionou ao país que houvesse progressos significativos no que concerne às políticas públicas relacionadas às pessoas com deficiência. Segundo dados do Centro de Reabilitação de Gaia (CRPG), foram criados e renovados os "modelos de abordagem e análise da questão das deficiências e incapacidades" (CRPG, 2007). A partir de parâmetros conceituais e políticos. Como resultado disso, o país foi capaz de observar uma mudança no impacto gerado pelas políticas públicas.

Apesar de todo esse progresso, segundo o Observatório da Deficiência e Direitos Humanos (ODDH), publicado em 2017, a "deficiência é o segundo motivo mais apontado para a discriminação em Portugal $(65 \%)$ e é aquele onde se registra a maior diferença em relação à média da UE (+15\%)" (PINTO, 2017, p. 8).

Esse quadro acaba se agravando porque recai sobre o portador de deficiência a obrigatoriedade de fornecer as informações necessárias para servirem de evidência sobre o ato discriminatório.

Dados apresentados pelo ODDH revelaram que houve, entre 2012 e 2015, um aumento no número de processos envolvendo atos de discriminação contra pessoas portadoras de deficiências, com base a Lei 46/2006 de Portugal (2006b). Contudo, no ano seguinte há uma queda nas taxas. A justificativa para a mudança do cenário se dá pelo fato de que a maioria foi arquivada por impossibilidade de resolução, falta de indícios, por 
desistência por parte da vítima, entre outros.

Vale destacar que o acesso à Justiça deve ser um "serviço que os magistrados devem prestar em nome da concretização dos direitos de cidadania" (DIAS, 2004, p. 50). Desse modo, a atuação dos operadores do Direito colabora para que os deficientes tenham o pleno acesso aos seus direitos.

No próximo tópico, serão apresentados dados estatísticos que corroboram com as questões anteriormente levantadas.

\section{Estatísticas da deficiência em Portugal}

Em comparação a todos os tipos de deficiências, em Portugal observa-se uma maior incidência de deficientes visuais e motores, sendo estes últimos relacionados diretamente aos ex-combatentes. Entre as entidades criadas voltadas para estes cidadãos está a ADFA (Associação dos Deficientes das Forças Armadas), criada em 1974; posteriormente, tem-se a Comissão Nacional de Deficientes Sinistrados no Trabalho (CNDST) em 1976; a CCNOD (Comissão Coordenadora Nacional dos Organismos de Deficientes) e a ACAPO (Associação de Cegos e Amblíopes de Portugal), na década de 1980; e, década de 1990, a Federação Portuguesa das Organizações de Surdos (FPOS).

Os soldados que voltaram deficientes das guerras mundiais ocorridas no século XX, necessitavam de uma pronta resposta do Estado para a sua assistência, o que acabou se estendendo para o restante da população que também possuía alguma deficiência (PEREIRA; ALBUQUERQUE, 2017).

Contudo, esse movimento em prol da deficiência ocorrido em Portugal não foi suficiente para aplacar as dificuldades pelas quais os deficientes estavam sujeitos, como demonstra Fontes:

[...] desde os anos 1980 as mudanças reais nas vidas das pessoas com deficiência em Portugal têm sido mínimas: os benefícios sociais são insuficientes para elevar a vida das pessoas com deficiência acima da linha de pobreza; os problemas no acesso ao emprego mantêm-se; e permanece a insidiosa exclusão de um sistema de ensino que não considera as suas necessidades e de um mercado de trabalho que exclui a diferença (FONTES, 2010, p. 95).

Diante disso, é possível observar que houve um efeito paliativo ou compensatório feito por meio de indenizações, e não uma solução definitiva ou mesmo iniciada por parte do Estado por meio de políticas sociais voltadas para os deficientes, como ocorreu na década de 1970.

Esse cenário não ficou restrito a Portugal. Pelo contrário, era visto em vários países onde "discursos e práticas dirigidos às pessoas com deficiência começaram a enfatizar a necessidade destas serem socialmente reabilitadas e integradas" (MARTINS, 2006). E é nesse contexto de reabilitação que as políticas públicas ainda se amparam.

SegundoFontes(2009), na décadade2000Portugal tinha quase 635.000 cidadãos portadores de alguma deficiência, o que corresponde a aproximadamente $6,1 \%$ da população do país à época. Com os avanços da medicina e o aumento da expectativa de vida das pessoas em todo o mundo, o país, com o passar dos anos, teria a expectativa de um aumento significativo desse índice.

Esses dados podem ser explicados devido ao fato de que Portugal considera, no âmbito da deficiência, as restrições, incluindo motoras, comuns às pessoas com idades mais avançadas, especialmente àquelas que não têm acesso a atividades físicas e de reabilitação.

A distribuição da população com deficiência por região (população com 5 ou mais anos) segue a mesma tendência que a distribuição da população total residente com 5 ou mais anos, com uma maior incidência populacional na região Norte (34\%), seguida do Centro (26\%), da Área Metropolitana de Lisboa (24\%), Alen $\neg$ tejo (8\%), Algarve (4\%) e Regiões AutónomasdosAçores(2\%)edaMadeira(2\%)(PINTO,2010).

Além da deficiência propriamente dita, os portadores também podem apresentar limitações em seu dia a dia. São fatores que podem impedi-los de socializar-se ou mesmo de exercer funções básicas, além de se locomover, sendo necessário, então, que sejam adotadas ações voltadas para a reabilitação, a educação direcionada e especial, e a criação de centros onde os deficientes possam realizar atividades que colaborem com a melhora nas suas condições globais de saúde e bem-estar.

O ODDH revelou que as mulheres estão em maior número quando observada a parcela da população portadora de deficiência ou incapacidade em Portugal, que possui pelo menos uma dificuldade no seu cotidiano, como pode ser observado no Quadro 1.

Quadro 1. Estatísticas acerca das dificuldades na população com 5 anos ou mais que é portadora de deficiência em Portugal (PINTO, 2010).

\begin{tabular}{|l|c|c|}
\hline \multicolumn{1}{|c|}{ Dificuldade } & Homem & Mulher \\
\hline Andar ou subir degraus & $7 \%$ & $11 \%$ \\
\hline Ver & $5 \%$ & $6 \%$ \\
\hline Memória ou concentração & $7 \%$ & $12 \%$ \\
\hline Ouvir & $5 \%$ & $8 \%$ \\
\hline Tomar banho ou vestir-se sozinho & $4 \%$ & $6 \%$ \\
\hline Compreender os outros ou fazer-se & $3 \%$ & $4 \%$ \\
compreender & & \\
\hline
\end{tabular}


Dados relevantes acerca dos direitos das pessoas com deficiência em Portugal registrados pelo ODDH revelaram aspectos alarmantes, compilados no Quadro 2, que demonstram a necessidade de políticas públicas para melhorar a condição geral dos portadores de deficiência no país, em especial no que diz respeito à inclusão.

Quadro 2. Estatísticas dos Direitos Humanos das pessoas com deficiência em Portugal (PINTO, 2010).

\begin{tabular}{|c|c|}
\hline Fator & Descrição \\
\hline Discriminação & $\begin{array}{l}\text { Em 2016, foram realizadas } 284 \text { queixas de } \\
\text { discriminação com base na deficiência. }\end{array}$ \\
\hline Educação & $\begin{array}{l}\text { Persiste uma grande disparidade de gênero na } \\
\text { população estudantil com necessidades educativas } \\
\text { especiais, com sub-representação feminina: } 38 \% \text { de } \\
\text { alunas para } 62 \% \text { de alunos. }\end{array}$ \\
\hline Emprego & $\begin{array}{l}\text { O desemprego registrado desceu } 18,8 \% \text { entre } 2011 \text { - } \\
2016 \text { para a população geral, mas aumentou } 26,7 \% \\
\text { na população com deficiência. }\end{array}$ \\
\hline $\begin{array}{l}\text { Condições de vida e } \\
\text { proteção social. }\end{array}$ & $\begin{array}{l}\text { O maior risco de pobreza é identificado entre as } \\
\text { pessoas com deficiência que residem em agregados } \\
\text { com baixa intensidade laboral }(23,1 \%) \text { ou baixo } \\
\text { rendimento }(24,8 \%) \text {. } \\
\text { O risco de pobreza e exclusão é experienciado } \\
\text { sobretudo, em agregados com pessoas com } \\
\text { deficiências graves }(36,5 \%) \text {. }\end{array}$ \\
\hline
\end{tabular}

A questão das condições financeiras precárias dos deficientes e o reflexo na sua condição de vida também são reconhecidos em outros países europeus, não sendo um quadro específico de Portugal.

Regra geral, os cidadãos portadores de deficiências estão mais expostos a situações de pobreza que os restantes cidadãos europeus, têm menos oportunidades não só no mercado de trabalho, mas também no acesso a serviços fundamentais como uma educação com as condições essenciais, a rede de transportes ou o mercado imobiliário de habitação (EUROCID, 2015, online).

Acerca dos dados sobre a deficiência em Portugal registrados pelo ODDH, observa-se que a maior parte da população que possui alguma deficiência é feminina. $\mathrm{O}$ levantamento feito pelo documento em questão mostrou que na faixa etária dos acima de 65 anos, 55\% das pessoas com deficiência são mulheres, enquanto nos outros grupos a média é mais equilibrada.

\section{Cidadania}

A cidadania pode ser descrita como sendo o meio pelo qual a sociedade alcança a sua identificação perante o Estado de forma participativa e consciente e recebe, em contrapartida, o acesso à segurança, educação, previdência e saúde, direitos sociais previstos na Constituição, mas também os econômicos, que envolvem o direito a ter um emprego no qual receberá um salário justo (PORTUGAL, 2006a, ROSÁRIO, 2015).

O conceito de cidadania pode receber outras definições, a depender da perspectiva analisada. Contudo, apesar dos mais variados vieses, a cidadania terá sempre como base alguns princípios básicos, como a igualdade entre as pessoas (FISHMAN/ HAAS, 2012).

Segundo a ONU (Organização das Nações Unidas), alguns fatores acabam colaborando para que os deficientes não tenham um pleno acesso à cidadania, que se relacionam às suas condições de vida. Para a instituição, a "ignorância, o abandono, a superstição e o medo, que estão entre os factores que ao longo da história da deficiência isolaram as pessoas com deficiência e retardaram o seu desenvolvimento" (ONU apud DIAS, 2011, p. 13).

Os três pilares para a conquista da cidadania plena são a educação, a proteção social, que deve ser dada pelo Estado, e o emprego. Como foi observado até o momento, não faltam diplomas legais que garantam aos portadores de deficiência o acesso a estes pilares. Tratam-se de direitos garantidos que devem ser respeitados pelo Estado e pelos cidadãos.

Contudo, durante a sua vida, o portador de deficiência acaba esbarrando em empecilhos que o impedem de ter acesso aos seus direitos, à sua cidadania. Correia (2010) concorda que o Estado não tem promovido meios de atender às necessidades educacionais básicas das crianças deficientes por meio da inclusão. A falta real de adequação dos sistemas de ensino regulares para a inclusão de pessoas com deficiências é um dos exemplos que acaba colaborando para que essas pessoas fiquem à margem da sociedade em termos de direitos.

Outro dado a ser observado é o fato de os profissionais, que deveriam estar preparados para lidar com alunos deficientes, não terem acesso a recursos que são necessários para a inclusão; quando possuem, são escassos.

Como resultado, verificam-se não apenas taxas de abandono escolar que tendem a ser elevadas entre as pessoas com deficiência, mas também carências de aprendizagem, de saberes específicos necessários de formas alternativas de realização, sendo que, porvezes, devido a algum facilitismo, as 
competências adquiridas nem sequer correspondem aos níveis de escolaridade obtidos pelos alunos (MARTINS, 2006,p. 24).

O mesmo cenário se observa nos demais níveis de ensino, culminando em uma série de desigualdades, tanto no que diz respeito ao acesso ao emprego quanto ao acesso à formação, inclusive no nível superior. Tratase de um problema grave que impede os deficientes de terem acesso àquilo que está descrito em diversos diplomas legais já listados neste artigo, sendo, desse modo, uma questão legal que deve ser cobrada do Estado (CORREIA, 2010).

Vale destacar que, apesar das dificuldades apresentadas, em Portugal as mudanças ocorridas com o objetivo de introduzir um conceito de educação especial tiveram início na década de 1960, mas só foram oficializadas realmente por meio de alterações ocorridas na Constituição da República em 1976. Contudo, mesmo depois de tantas décadas, na prática, muitos deficientes ainda aguardam uma oportunidade de se tornarem realmente cidadãos (PORTUGAL, 2006a).

NoBrasil,observa-sea falta deacessoàreabilitação e à habilitação profissional devido às carências no campo educacional. Além disso, há o preconceito dos próprios empregadores em disponibilizar vagas para deficientes. Esse tipo de discriminação acaba colaborando para que mais deficientes, mesmo capacitados, acabem ficando à margem do mercado de trabalho no país, o que não é muito diferente do que se observa em outros países (SILVA JUNIOR, 2011).

Independentemente da forma de discriminação, as barreiras sociais e físicas afetam cerca de um em cada seis cidadãos europeus, isto é, aproximadamente 80 milhões de pessoas. Paralelamente, a recessão econômica tem produzido um impacto adverso na situação das pessoas com deficiência, circunstância que contribui para acentuar a urgência de tomada de decisões neste domínio (EUROCID, 2019, online).

Em Portugal, além das questões relacionadas ao fato de que grande parte dos deficientes está nas classes sociais menos favorecidas, quando estas conseguem alcançar a profissionalização, acabam se deparando com uma série de fatores que as impedem de exercer sua profissão, como barreiras arquitetônicas e de comunicação, e dificuldades no acesso aos transportes públicos (MARTINS, 2006).

Fontes (2009) concorda com essa colocação e vai além ao afirmar que a pobreza associada à deficiência é um resultado da forma como a própria sociedade vê e se relaciona com o deficiente, assim como as "barreiras físicas, sociais e psicológicas erigidas relativamente à deficiência e às pessoas com deficiência" (Ibidem, p. 74)

\section{A cidadania como meio de inclusão dos deficientes em Portugal}

A inclusão social está relacionada à forma como os membros de uma sociedade estão nela inseridos. Desse modo, no que se refere aos deficientes, diante da realidade apresentada até este momento, foi possível observar que estes indivíduos só podem se considerar incluídos se tiverem acesso a todas as oportunidades oferecidas aos cidadãos sem deficiências (PORTUGAL, 2006a; DIAS, 2011).

Essa exclusão do deficiente na história referese do que Martins (2006) observa como sendo uma discriminação pautada em questões genéticas, ao contrário do que acontece com a discriminação racial ou por opção sexual. No caso da deficiência, o sujeito acaba sendo privado de uma série de experiências, causando angústia e sofrimento, mas, também, de questões relacionadas ao acesso aos direitos constitucionais, como saúde e educação.

Entre as dificuldades que impediram que os deficientes estivessem verdadeiramente incluídos na sociedade, com acesso a plenos direitos, está no fato de que durante muito tempo o tema era visto como algo individual, e que deveria ser tratado diretamente com profissionais e não como uma questão social capaz de alcançar um grande número de indivíduos que estavam tendo seus direitos constitucionais cerceados (MARTINS, 2006).

Para Fontes (2010), durante o período ditatorial vivido por Portugal, as políticas públicas voltadas para os deficientes são consideradas como praticamente inexistentes, sendo esse um período em que o Estado colocou esse grupo em uma "situação de exclusão social, mas também, numa difícil situação económica, por vezes abaixo do limiar de pobreza" (FONTES, 2010, p. 92).

Fontes (2015) ressalta em outro estudo que "o questionamento da naturalização da exclusão social a que as pessoas com deficiências estão sujeitas nas sociedades ocidentais tem lugar a partir dos anos de 1970" (FONTES, 2010, p. 92), especialmente devido ao desenvolvimento dos denominados Estudos da Deficiência. Estes ocorrem nos Estados Unidos e também na Inglaterra graças aos movimentos feitos por deficientes na década de 1960.

Em outros países europeus na década de 1960, foram criadas comunidades voltadas para os deficientes, trazendo à luz uma questão social e de solidariedade entre os cidadãos. Em Portugal, os deficientes, em especial os ex-combatentes, como mencionado anteriormente, buscaram agir isoladamente, criando instituições voltadas para os seus interesses e não da sociedade como um todo, ou seja, para todos os cidadãos deficientes (FONTES, 2010). 
Hespanha (2001) comenta que, em decorrência da revolução ocorrida em 1974, Portugal passou por uma fase denominada pelo autor de quase-EstadoProvidência, ou seja, tardia e envolta em uma situação de crise em todo o mundo quando comparado a outros países europeus. O país apresentou um quadro de ineficiência quando observado os índices de segurança proteção social.

Para além de factores políticos e financeiros condicionantes do Estado-Providência português, identifico a presença de outro motivo estrutural - o predomínio de um entendimento médico e individual da deficiência. Tal entendimento sugere uma abordagem às vidas das pessoas com deficiência em termos de incapacidade e inadequação(FONTES, 2009, p.84).

Apesar de que se tenha observado um recuo nas políticas sociais em Portugal na década de 1980, não se pode deixar de reconhecer que, mesmo nesse período da história do país (década de 1970), algumas medidas foram tomadas em prol da deficiência, como o DecretoLei 513-L (PORTUGAL, 1979) de 26 de dezembro de 1979, em que se implantou no país o Serviço Nacional de Saúde. A partir deste destaca-se a criação do Esquema Mínimo de Segurança Social, em que ficou previsto um subsídio que deveria ser concedido mensalmente aos menores deficientes.

Para analisar a questão da inclusão dos deficientes, é preciso que seja feita uma reflexão dos fatos que impedem o acesso desse grupo aos seus direitos constitucionalmente garantidos e ratificada por tantos outros diplomas legais. É importante verificar quais os motivos que levam um sujeito a ter seus direitos negados, pois isso tem como consequência a discriminação e o preconceito, sendo os principais desafios a serem enfrentados (DIAS, 2011).

Os "movimentos normalizantes" próprios da medicina vieram a estruturar os movimentos dominantes que definem os itinerários da integração social. As práticas curativas da medicina baseiam-se na supressão da anormalidade e na restituição do corpo a um desejável estado de normalidade. A questão é que, embora o exercício da medicina, enquanto prática curativa, pouco intervenha nos corpos descritos como deficientes, são os seus modelos e discursos que, até hoje, informam as respostas sociais dominantes à deficiência (MARTINS, 2006, p. 22).

Vale lembrar os comentários de Candeias (2009), quando este afirma que a "inclusão é um processo que respeita e valoriza a diferença e todos têm um papel a desempenhar na sociedade" (Ibidem, p. 10). Além disso, diz respeito à boa qualidade de vida das pessoas, seja nos níveis econômico, filosófico ou social. Impedir que os deficientes desempenhem seu papel é o mesmo que colaborar para a sua exclusão.

No que diz respeito à exclusão do deficiente no mercado de trabalho, esse cenário acaba tendo como resultado uma série de danos causados ao indivíduo, entre eles os danos psíquicos devido ao fato deste se sentir excluído da sociedade e impedido de exercer suas funções.

No que concerne ao Estado, a exclusão desses deficientes terá como consequência no futuro as despesas para que tenha as mínimas condições de subsistência. Desse modo, a inclusão do deficiente pode ser encarada como uma estratégia de gestão de recursos do Estado.

Em Portugal, políticas sociais baseadas na ideia de cidadania
das pessoas com deficiência são uma realidade ainda muito
recente, visível apenas a partir dos anos 2000 com a aprovação
de documentos como a Lei Anti-discriminação das pessoas
com deficiência (Lei 46/2006, 28/08/2006) ou o $1^{\circ}$ Plano
de Acção para a Integração das Pessoas com Deficiências
ou Incapacidade 2006-2009 (Resolução do Conselho de
Ministros 120/2006, 21/09/2006) (FONTES, 2010, p. 96).

Segundo dados do Gabinete de Estratégia e Planejamento, em 2015 mais de 87 mil pessoas receberam uma bonificação por deficiência em Portugal, quase $50 \%$ mais beneficiários que os registrados no ano de 2005 (ODDH). Essa bonificação é dada às famílias que possuem crianças ou jovens portadores de deficiência no país. Além do aumento nas taxas de bonificação, houve um aumento significativo no número de pessoas que recebem o subsídio mensal vitalício, saindo de quase 11 mil pessoas em 2005 para quase 14 mil em 2015.

Uma forma de conciliar justiça social e eficiência econômica seria permitir que as empresas que não cumprissem a cota contribuíssem para um fundo destinado a financiar ações voltadas às pessoas com deficiência. Nesse caso, aquelas que contratassem um número acima da cota legal receberiam um subsídio como incentivo para inclusão trabalhista adicional gerada (GOLDFAR, 2009, p. 152).

Tal citação mostra como medidas alternativas estão sendo tomadas para suprir a lacuna deixada pelo Estado nas medidas mais básicas constantes em vários diplomas legais. Estas medidas deveriam garantir aos indivíduos o acesso aos seus direitos como cidadão.

A mediação entre a cidadania e os órgãos de soberania
é uma vocação dos partidos políticos. A distância e a
falta de confiança que se estabeleceu entre estes dois
planos levanta questões quanto à capacidade destes em
desempenhar este papel mediador. Abre-se assim um
espaço para acções alternativas de defesa dos interesses
de categorias de cidadãos. Entre as forças sociais
que sustentam ações desta natureza encontram-se os
chamados movimentos sociais (FERREIRA, 2017, p. 15).

Para se garantir que o deficiente se sinta incluído, é preciso que haja uma integração entre Estado e sociedade. Isso se dá por meio de estratégias que promovam uma melhor qualidade de vida do deficiente, que envolve, entre outros fatores, o acesso à educação, às condições financeiras para ter uma casa acessível, e dar a essas pessoas acessos aos recursos básicos para 
que sejam incluídos na sociedade como os demais cidadãos (DIAS, 2011).

O cidadão portador de deficiência é, enquanto cidadão, essência e destinatário dos direitos humanos comuns a todos os cidadãos. No entanto, devemos ter presente a existência de direitos específicos daqueles cidadãos e da necessidade de especial proteção de todos os direitos fundamentais - não só destes específicos como dos comuns - do cidadão portador de deficiência (ROSÁRIO, 2015).

Trata-se de uma questão complexa relacionada diretamente aos valores universalmente garantidos, assim como aos conceitos relacionados à igualdade de oportunidades e direitos à cidadania. Vale destacar o que se prevê na Lei de Bases da Segurança Social portuguesa acerca da inserção social:

Artigo 12. ${ }^{\circ}$ Princípio da inserção social $\mathrm{O}$ princípio da inserção social caracteriza-se pela natureza activa, preventiva e personalizada das acções desenvolvidas no âmbito do sistema, com vista a eliminar as causas de marginalização e exclusão social e a promover a dignificação humana (PORTUGAL, 2017).

A inclusão é um processo muito complexo que configura diferentes dimensões, quais sejam, a ideológica, a sociocultural, a política e a econômica. É vista por muitos autores como um desafio para toda a sociedade que tem início especialmente no acesso à educação.

Por meio da inclusão dos deficientes ao sistema de ensino, tem-se um caminho aberto para a sua independência futura, ou seja, haverá condições de competir em igualdade no mercado de trabalho.

Vale destacar que a inclusão não deve ser algo almejado apenas pelos deficientes, mas um objetivo de toda a sociedade. A inclusão de deficientes nas escolas é um momento decisivo e privilegiado para a criação de cidadãos conscientes das necessidades de todos. Isso no futuro terá como resultado uma sociedade composta por adultos plenos de valores sociais, além de respeito e da certeza de que todos devem ter direito iguais de acesso à cidadania (DIAS, 2011).

Estamos perante uma lógica dominante que funda um investimento de saberes sobre as deficiências que, na impossibilidade da cura, propõe a reabilitação e, na impossibilidade da adesão à norma, propõe a possível supressão do desvio. Como essa supressão do desvio não equivale à efetiva restituição à normalidade, neste quadro a deficiência está fadada a não ser entendida como diferença, mas sim como fatal subalternidade (MARTINS, 2006, p. 22).

Quando observamos a inclusão de um princípio filosófico, vemos como definição a metáfora do "caleidoscópio", ou seja, a imagem sugere uma composição mais rica pela combinação e diversidade das partes e pelo movimento, obtendo-se composições novas e mais complexas.

A metáfora da inclusão sugere a imagem de uma sociedade em movimento, em constante transformação e construção, de enriquecimento pelas diferenças. Esse movimento implica, entre outras coisas: mudança de atitudes e constante reflexão, inclusive no contexto da prática pedagógica nas escolas para a inclusão dos deficientes, na modificação e na adaptação do meio.

A inclusão é baseada num sistema de valores que faz com que todos se sintam bem-vindos e que celebra a diversidade, cuja base é o gênero, a nacionalidade, a raça, a linguagem, a origem social, o nível de aquisição educacional ou a deficiência (PEREIRA; ALBUQUERQUE, 2017, p. 30).

Como mencionado anteriormente, o retorno de ex-combatentes deficientes das grandes guerras ocorridas no século XX deu início a uma mudança na visão e na necessidade de se criar centros de reabilitação dos militares, que foram aos poucos estendidos aos demais cidadãos. Foi a partir desse marco histórico que é possível começar a observar a criação de políticas públicas, mesmo que inicialmente se mostrassem insuficientes, e a criação de leis voltadas para os deficientes (MARTINS, 2006).

Eis alguns eventos mundiais que também colaboraram para a mudança no cenário da inclusão de pessoas com deficiências: a Conferência Mundial de Educação para Todos ocorridos, em 1990 na Tailândia, a Conferência de Salamanca, ocorrida em 1994 na Espanha, assim como outros eventos ocorridos em 1981, o denominado Ano Internacional da Pessoa com Deficiência.

No Brasil, o Estado criou meios sociais para estimular a inserção de pessoas com deficiências no mercado de trabalho e também nas universidades, tanto no âmbito público quanto privado, por meio do sistema de cotas.

Em Portugal, Martins (Ibidem) comenta que desde o ensino regular observa-se o que ele denomina de vazio legislativo, já que o Estado não atende as necessidades dos deficientes devido à falta de recursos materiais para os professores, que deveriam ser capacitados para lecionar para deficientes surdos ou cegos, por exemplo. Há também a falta de estruturas das próprias instituições, sem acessibilidade. A inclusão dos deficientes nas universidades portuguesas também carece de atenção à medida que depende basicamente da vontade de seus administradores.

Ovaziolegislativoexistentefazcomqueapenas4universidades em Portugal tenham desenvolvido, por sua iniciativa, estruturas de apoio às pessoas com deficiência, estruturas que não obedecem a uma qualquer lógica comum (Ibidem, p. 25).

Impedir o acesso à Educação pode ser visto como o primeiro passo para uma série de atos discriminatórios 
que perseguirão o deficiente por toda a sua vida. Isso ocorre à medida que, sem conhecimento básico, o deficiente não será capaz de exercer uma profissão e garantir por si mesmo seu sustento por meio de um emprego digno.

Para Martins e Fontes (2016), esses acontecimentos colaboram para uma situação contínua de exclusão do deficiente em Portugal, necessitando que políticas sociais voltadas para os deficientes que já existem, inclusive no âmbito da UE, sejam efetivamente implementadas para mudar essa realidade.

A UE da qual Portugal é membro estabeleceu uma série de estratégias e políticas públicas, que deveriam ser implementadas entre os anos 2010 e 2020. Estas visavam a promover a devida igualdade de direitos e oportunidades para os portadores de deficiência europeus, contudo, nem tudo foi alcançado até o momento.

Quadro 3. Estratégias e ações concretas formuladas pela UE (EUROCID).

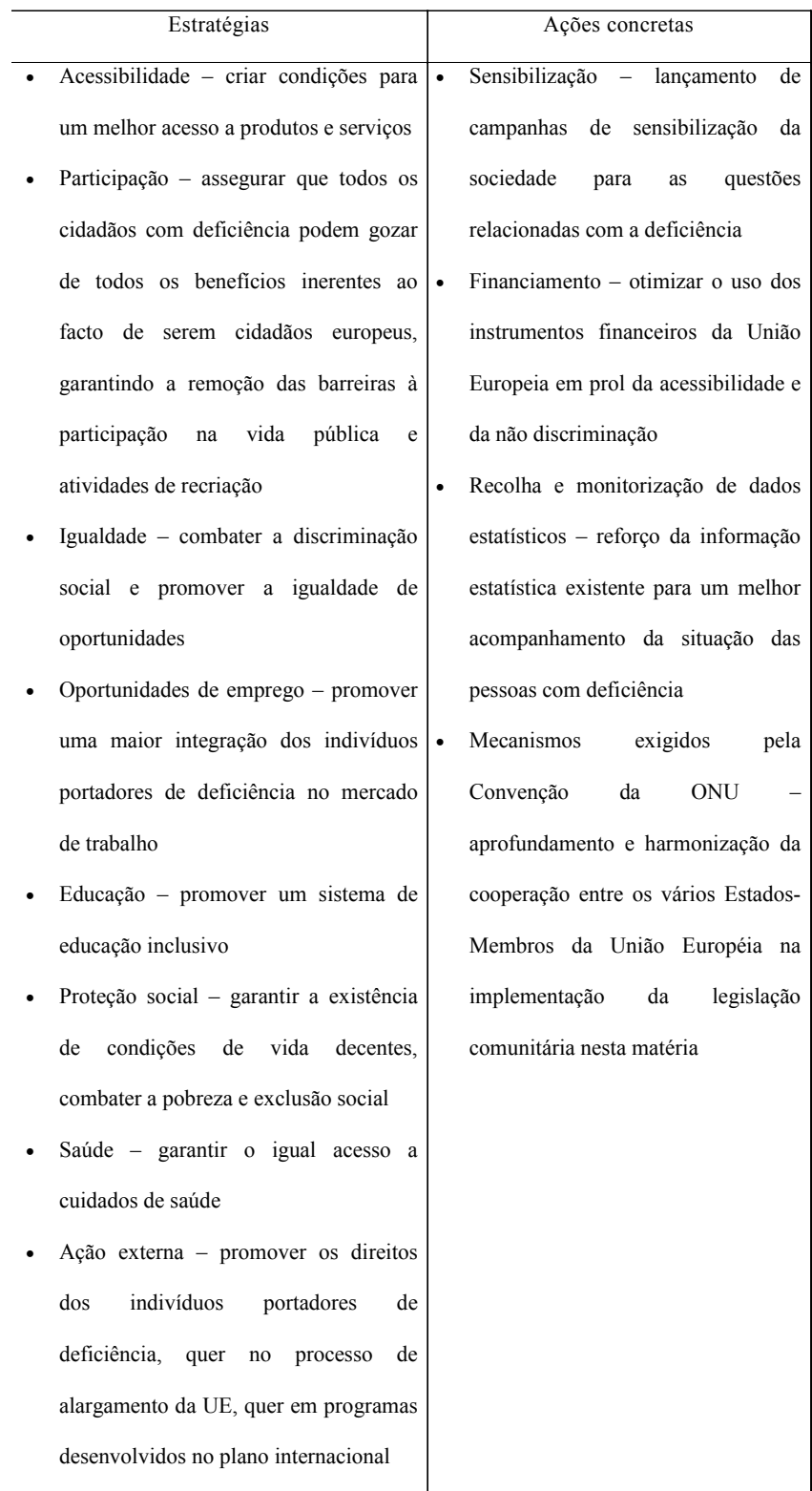

Além dessas estratégias, a Comissão Europeia também criou um programa que busca alcançar a igualdade de direitos para todos os cidadãos europeus, que tem como base tratados internacionais relacionados aos direitos humanos. Entre os objetivos do programa, estão: "promover a não discriminação; promover os direitos das pessoas com deficiência" (UE, 2014, p. 6).

Ainda sobre os dados revelados pelo ODDH, mencionado inicialmente neste estudo, em Portugal é bem baixo o número de pessoas portadoras de deficiência em pequenas empresas privadas. Contudo, quando observados os trabalhadores da administração pública, esse número aumenta significativamente, de até $1 \%$ para $2,3 \%$ (PINTO, 2017).

\section{Considerações finais}

Diante do que foi exposto neste artigo, foi possível observar que a educação, o emprego e o amparo social, por parte do Estado, são pilares imprescindíveis para que o deficiente esteja inserido na sociedade como todas as pessoas.

Sem acesso à educação, o deficiente dificilmente será capaz de ter seus direitos constitucionais garantidos, vindo de encontro a tudo o que prevê os diversos diplomas legais apresentados neste artigo. Além de se tratar de uma questão de direitos, cumprir o que está previsto na lei pode ser visto como estratégia de Estado à medida que, com acesso aos direitos garantidos, o cidadão não necessitará de subsídios governamentais para a garantia das mínimas condições de vida.

Cabe então aos operadores do Direito trabalhar para que os deficientes tenham seus direitos à cidadania garantidos desde o seu nascimento, independente da sua dificuldade e classe social.

Espera-se que este artigo colabore para o incentivo de futuros estudos acerca do tema, assim como para a compreensão da inclusão de deficientes como forma de garantir a sua cidadania.

\section{Notas}

1. Portugal. (1979). Op.cit. Artigo 9. (Subsídio mensal a menores deficientes) 1 - É concedido por direito próprio um subsídio mensal a menores deficientes de idade não superior a 14 anos a quem não seja reconhecido esse direito pelos regimes de protecção social que abranjam os pais ou equiparados, respeitando-se, para o efeito, as condições gerais de atribuição do subsídio mensal vitalício estabelecidas no Decreto-Lei n. ${ }^{\circ}$ 197/77, de 17 de Maio, e demais legislação complementar. 2- $\mathrm{O}$ subsídio previsto no número anterior é substituído pela pensão social sempre que satisfeitas as condições de atribuição desta. 3 - Não se concretizando, nos termos do número anterior, a atribuição da pensão social, é mantido o direito ao subsídio mensal até à maioridade, satisfeitos os restantes condicionalismos deste subsídio

\section{Referências}

BRASIL. Convenção sobre os Direitos das Pessoas com Deficiência 
Protocolo Facultativo à Convenção sobre os Direitos das Pessoas com Deficiência: decreto legislativo $\mathrm{n}^{\circ} 186$, de 09 de julho de 2008: decreto $\mathrm{n}^{\circ}$ 6.949, de 25 de agosto de 2009. Brasília: Secretaria de Direitos Humanos, Secretaria Nacional de Promoção dos Direitos da Pessoa com Deficiência, 2011.

AMIRALIAN, M.L.T. et al. Conceituando deficiência. Revista de Saúde Pública, n, 34, v.1, p. 97-103, 2000.

CANDEIAS, A. Escola inclusiva: contributos para a sua implementação. Évora: Centro de Investigação em Educação e Psicologia/Universidade de Évora, 2009.

CORREIA, Luis Miranda de. Educação Especial e Inclusão. ( $2^{\mathrm{a}}$ Ed, revista e actualizada). Porto: Porto Editora, 2010.

CRPG. Centro de Reabilitação Profissional de Gaia. Mais Qualidade de Vida para as Pessoas com Deficiências e Incapacidades. Uma Estratégia para Portugal. Vila Nova de Gaia: ISCTE, 2007.

DIAS, L.P.F Inclusão social de cidadãos portadores de deficiência(s) residentes no concelho de Miranda do Douro. Bragança: Instituto Politécnico de Bragança - Escola Superior de Educação, 2011.

DIAS, P. O mundo dos magistrados. A evolução da organização e do autogoverno judiciário. Coimbra: Almedina, 2004.

DINIZ, D.; SQUINCA, F.; MEDEIROS, M. Deficiência, Cuidado e Justiça Distributiva. Série Anis 48. Brasília: Letras Livres, 2007.

EUROCID. Cidadãos com deficiência na União Europeia. Disponível em: http://www.eurocid.pt/pls/wsd/wsdwcot0.detalhe?p_cot_id=7628. Acesso em: 05 Mar. 2019

EUROPEAN Comission. Justice: Rights, equality and citizenship Programme 2014-2020: objective of the Programme. Disponível em: http:// ec.europa.eu/justice/grants1/programmes-2014-2020/rec/index_en. $\mathrm{htm}$. Acesso em:10 Mar. 2019.

FERREIRA, A.C et al. (Orgs.) Direito, Justiça, Cidadania: O Direito na Constituição da Política. Atas do Primeiro Encontro da Secção "Sociologia do Direito e da Justiça" da APS. n.19, Universidade de Coimbra. Coimbra: Editorial Board, 2017.

FISHMAN, G.E.; HAAS, E. Cidadania. Educ. Real., Porto Alegre, v. 37, n. 2, p. 439-466, maio/ago, 2012.

FONTES, Fernando. Pessoas com deficiência e políticas sociais em Portugal: da caridade à cidadania social. Revista Crítica de Ciências Sociais, 86, p. 73-93, Setembro 2009.

FONTES, Fernando. Deficiência e Cidadania: o papel do movimento de pessoas com deficiência em Portugal. Actas do Seminário Geografias de Inclusão: desafios e oportunidades. Lisboa: Faculdade de Ciências Sociais e Humanas, Universidade Nova de Lisboa, 2010.

FONTES, Fernando., MARTINS, Bruno. Deficiência e inclusão social: Os percursos da lesão medular em Portugal. Sociologia, Problemas e Práticas, n. ${ }^{\circ} 77$, maio, 2015.

GOLDFARB, C. L. Pessoas portadoras de deficiência e a relação de emprego. O sistema de cotas no Brasil. Curitiba: Juruá, 2009.

HESPANHA, Pedro. Mal-estar e Risco Social num Mundo Globalizado: Novos problemas e novos desafios para a teoria social, Apud Boaventura de Sousa Santos (org.), Globalização - Fatalidade ou Utopia?. Porto: Edições Afrontamento, 2001.

MARTINS, B. S. E se eu Fosse Cego: Narrativas Silenciadas da Deficiência. Porto: Afrontamento, 2006.

MARTINS, B. S. A deficiência e as políticas sociais em Portugal: retrato de uma democracia em curso. Revista Educação, Cultura e Comunicação da Universidade de Coimbra, v.9, n.1, jan-jun 2017.

MARTINS, Bruno Sena; FONTES, Fernando. (Orgs.). Deficiência e emancipação social - Para uma crise da normalidade. Coimbra: Almedina, 2016.

OBSERVATÓRIO DA DEFICIÊNCIA E DOS DIREITOS HUMANOS (ODDH). Estatísticas sobre Deficiências ou incapacidades. Disponível em: http://oddh.iscsp.ulisboa.pt/index.php/pt/2013-04-24-18-50-23/outras- publicacoes/item/281-estat $\%$ C3\%ADsticas-sobre-defici $\%$ C3\%AAncias-ouincapacidades. Acesso em:11 Fev. 2019.

ONU. ORGANIZAÇÃO DAS NAÇÕES UNIDAS. Declaração de Salamanca. Enquadramento da acção na área das necessidades educativas especiais. Conferência mundial sobre necessidades educativas especiais acesso e qualidade. 1994. Disponível em: http://portal.mec.gov.br/seesp/ arquivos/pdf/salamanca.pdf . Acesso em:07 Mar. 2019.

ONU. ORGANIZAÇÃO DAS NAÇÕES UNIDAS. Convenção sobre os Direitos das Pessoas com Deficiência. Protocolo Facultativo à Convenção sobre os Direitos das Pessoas com Deficiência: decreto legislativo $\mathrm{n}^{\circ} 186$, de 09 de julho de 2008: decreto $\mathrm{n}^{\circ}$ 6.949, de 25 de agosto de 2009. -- 4. ed., rev. e atual. - Brasília: Secretaria de Direitos Humanos, Secretaria Nacional de Promoção dos Direitos da Pessoa com Deficiência, 2011.

OMS. ORGANIZAÇÃO MUNDIAL DA SAÚDE. Classificação Internacional de Funcionalidade, Incapacidade e Saúde. CIF. Lisboa: 2004.

PEREIRA, Carlos Eduardo Candido; ALBUQUERQUE, Cristina Maria Pinto. A inclusão das pessoas com deficiência: panorama inclusivo no ensino superior no Brasil e em Portugal. Educar em Revista, Curitiba, Brasil, n. especial 3, p. 27-41, dez. 2017.

PINTO, P. C.; Pinto, T. J. Pessoas com deficiências em Portugal: indicadores de Direitos Humanos 2017. Instituto Superior de Ciências Sociais e Políticas (ISCSP), nov. 2017

PORTUGAL. Decreto-Lei 513-Lde26 de dezembro de 1979. Disponível em: https://dre.pt/pesquisa/-/search/430015/details/normal?p_p_auth=Iy5xq5eu. Acesso em: 27 Ago. 2019

PORTUGAL. Lei 319/91. Disponível em: https://dre.pt/pesquisa/-/ search/403296/ details/maximized. Acesso em: 08 Mar 2019.

PORTUGAL. Lei 38/2004. Disponível em: https://dre.pt/pesquisa/-/ search/480708/ details/maximized. Acesso em: 08 Mar 2019.

PORTUGAL. Constituição. VII Revisão Constitucional. 2005. Disponível em: https://www.parlamento.pt/Legislacao/Paginas/ ConstituicaoRepublicaPortuguesa.aspx. Acesso em: 05 Mar 2019.

PORTUGAL. Código Civil Português (Atualizado até a Lei 59/99, de 30/06). 2006a. Disponível em: https://www.igac.gov.pt/ documents/20178/358682/C\% $\quad$ C3\%B3digo+Civil.pdf/2e6b36d8-876b433c-88c1-5b066aa93991. Acesso em:10 Fev. 2019.

PORTUGAL. Lei 46/2006b. Disponível em https://dre.pt/pesquisa/search/540797/details/maximized. Acesso em: 08 Mar 2019.

PORTUGAL. Ministério do Trabalho e da Solidariedade Social. $\mathbf{1}^{\mathbf{0}}$ Plano de Acção para a Integração das Pessoas com Deficiências ou Incapacidade. Lisboa: CID/DGEEP, 2006c.

PORTUGAL. Convenção sobre os direitos das pessoas com deficiência. 2011. Disponível em: http://www.inr.pt/content/1/1187/convencao-sobre-osdireitos-das-pessoas-com-deficiencia. Acesso em: 05 Mar 2019.

PORTUGAL. Lei 4 de 16 de janeiro de 2017. Leide Bases da Segurança Social. Disponível em: http://www.appdh.org.pt/img/ Leibasessegurancasocial.pdf. Acesso em: 03 Mar. 2019.

ROSÁRIO, Pedro Trovão. Cidadania e deficiência. Empório do Direito. Publicado em 16 jul 2015. Disponível em: https://emporiododireito.com.br/ leitura/cidadania-e-deficiencia. Acesso em: 25 Ago. 2019.

ROSÁRIO, Pedro Trovão. O direito a ser esquecido. Revista do Direito. Santa Cruz do Sul, v. 3, n. 53, p. 121-139, set./dez, 2017.

SILVA JUNIOR, R. O. Inserção do deficiente físico no mercado de trabalho. Coimbra: Universidade de Coimbra, 2011. 